\title{
Interactive Model Used in Maintenance Planning of Facades Based on Virtual Reality Technology
}

\author{
Alcínia Zita Sampaio, Augusto M. Gomes and Ana Rita Gomes \\ Department of Civil Engineering and Architecture, Technical University of Lisbon, Lisbon 1049-001, Portugal
}

\begin{abstract}
A virtual reality model was created in order to help in the maintenance of exterior closures and interior finishes of walls in a building. It allows the visual and interactive transmission of information related to the physical behavior of the elements, defined as a function of the time variable. To this end, the basic knowledge of material most often used in walls, anomaly surveillance, techniques of rehabilitation, and inspection planning were studied. This information was included in a database that supports the periodic inspection needed in a program of preventive maintenance. The results are obtained interactively and visualized in the virtual environment itself. This work brings an innovative contribution to the field of maintenance supported by emergent technology.
\end{abstract}

Key words: Construction, maintenance, cooperative visualization, virtual reality, decision-making.

\section{Introduction}

The main aim of a research project, now in progress at the Department of Civil Engineering of the Technical University of Lisbon, is to develop virtual models as tools to support decision-making in the planning of construction management and maintenance. A first prototype concerning the lighting system has already been completed [1]. A second prototype concerning the maintenance of the closure of walls, both interior walls (and facades, is now being developed. This paper describes this part of the project. The interactive model integrates VR (virtual reality) technology, the EON system of the EON Reality Company [2], and an application implemented in VB (visual basic) language. The model allows interaction with the 3D geometric model of a building, visualizing components for each construction. It is linked to a database of the corresponding technical information concerned with the maintenance of the materials used as exterior closures and interior finishes. The principal

Corresponding author: Alcínia Zita Sampaio, assistant professor, research fields: information technology in construction, BIM, virtual reality technology, and maintenance. E-mail: zita@civil.ist.utl.pt. objective of the interactive VR prototype is to support decision-making in the maintenance domain.

The present project aims to bring important contributions to this domain, through the implementation of virtual models able to relating the behavior of materials, their characteristics, anomalies and repair work to each other. During this work the basic knowledge of the topics involved, such as aspects related to the materials, the techniques of rehabilitation and conservation and the planning of maintenance is outlined and discussed in addition, methods of interconnecting this knowledge with the virtual model are explored. The prototype for walls was trialed in a concrete project. This kind of building element has a continuous lifestyle, so requires the study of preventive maintenance (the planning of periodical local inspections) and of corrective maintenance with repair activity analysis. The model facilitates the visual and interactive access to results, supporting the definition of inspection reports. It will be possible in the future to apply this to other building situations whether in new constructions or those needing rehabilitation.

\section{VR in Construction and Maintenance}

The performance of the maintenance of a building 
has been increased through the application of new modeling concepts, particularly the incorporation of VR techniques and the addition of time as a factor to be considered in the strategy of building conception. In the same way, 3D models have been developed, related to the time parameter, designated $4 \mathrm{D}$ models [3], focused in the beginning, basically, on planning the construction process. The geometric model of construction is presented as a progression of steps in its physical evolution following planning. The University of Stanford [4] and the Finnish Centre of Investigation VTT [5], have presented concrete applications in the design phase with considerable befits relevant to communication between specialists, constructors and promoters. In the construction domain, the VR models are used to show the physical evolution of the building, through 4D models, in different phases of its construction following specific planning [6] and the simulation of the operational evolution of the associated construction processes [7]. In the area of architecture, VR models are generally applied to the visualization of static physical models in the definition of itineraries of walk-through, as a means of transmitting the functional and geometric aspect of the building.

In addition, VR technology has also been applied as a complement to 3D modeling, leading to better communication between the various stakeholders in the process, whether in training or in professional practice. This task is particularly relevant to the presentation of processes which are defined through sequential stages as generally is the case in the learning of new curricular subjects. In professional contexts, note the contribution in Architecture/Engineering, to support for conception, presenting the plan or following the progress of construction [8].

In the maintenance domain some researches have been including visual interaction: Anna-Liisa Linholm [9] describes the creation process of an interactive model for identifying the added value of corporate real estate management and implement it in a case organization, testing whether it works in practice; Visualization of building maintenance through time is the topic of the researching activity of Rad [10], Khosrowshahi [11] focus the research VR application on lighting and paintings of interior wall maintenance.

One of the more recent targets of investigation is in fact, research into the sharing of data between applications, which can be manipulated by means of a common interface, as a way of rendering 4D tools efficacious and of wide use. Virtual reality is seen today as an integrating technology, with great potential for communication between project participants, and most recently, as a tool for the support of decision-making, made possible by the integration of distinct computer applications in the virtual model. In this context, the present work presents the development of a system concerning maintenance based on VR technology, involving knowledge of the physical aspects of materials, in particular, those which refer to wear and tear (a function of time, use and environmental factors), integrating them in digital spatial representations. In this way, the indisputable advantage of the ease interpretation and perception of space provided by the visualization of 3D models, and the technical content underlying the real characteristics of the observed elements are brought together.

\section{Interactive and Collaborative Models}

Virtual Reality technology can support the management of data that is normally generated and transformed or replaced throughout the lifecycle of a building. This technology becomes an important support in the management of buildings allowing interaction and data visualization. At present, the management of building planning can be presented in a 3D form and various materials can be assigned to the fixtures and furnishing enabling the user to be placed in the virtual building and view it from inside as well as outside. This study contemplates the incorporation of the 4th dimension, that is, time, into the concept of visualization. The focus of the work is on travelling 
through time: the ability to view a product or its components at different points in time throughout their life. It is envisaged that the incorporation of the time dimension into 3D visualization will enable the designer/user to make more objective decisions about the choice of the constituent components of the building. In maintenance the time variable is related to the progressive deterioration of the materials throughout the building's lifecycle.

The present prototype [12] incorporates interactive techniques and input devices to perform visual exploration tasks. To support this system a data base was created which included a bibliographic research support made in regard to the closure materials used in the interior and exterior walls of a building, anomalies concerning different kinds of covering material, and corrective maintenance. Repair activities were also studied. The programming skills of those involved in the project had to be enhanced so that they could achieve the integration of the different kinds of data bases needed in the creation of the interactive model.

The 3D model linked to a data base concerning maintenance produces a collaborative virtual environment, that is, one that can be manipulated by partners interested in creating, transforming and analyzing data in order to obtain results and to make decisions. For example, inspection reports can be defined and consulted by different collaborators. The process of developing the prototype interface considers these purposes. The developed prototype associates the characteristics of the coating component of the exterior and interior walls to activities concerning the maintenance of buildings (Fig. 1).
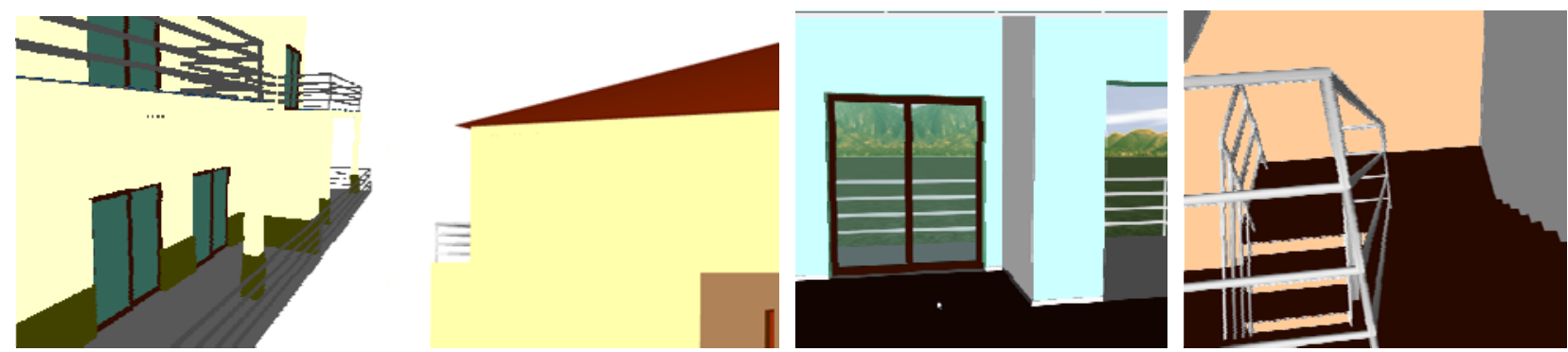

Fig. 1 3D model of the house: coating elements of exterior and interior walls.

\section{Wall Maintenance Prototype}

Facade coatings play an important role in the durability of buildings, since they constitute the exterior layer that ensures the protection of the wall against the aggressive actions of physical, chemical or biological nature. Naturally, they should also give the facade the required decorative effect. Since this building component is exposed to bad atmospheric conditions it frequently shows an evident degree of deterioration, requiring maintenance interventions. To perform maintenance activities a survey of failures in the building must be conducted in order to arrive at the best solution for repair and maintenance.

In order to better understand the operation of facade coating, bibliographic research of materials usually applied to facade coatings was carried out and a table of characteristics of these was drawn up. Subsequently, a survey was made of anomalies, probable causes, solutions and methods of repair for each of the coatings studied. The visualization of the maintenance data of a building and the impact of time on the performance of these exterior closure materials require an understanding of their characteristics [13] (Fig. 2).

- Types of material: painted surfaces, natural stone panels and ceramic wall tiles;

- Application processes: stones (panel, support devices, adherent products,... ), ceramic tiles (fixing mechanism, procedures,...), painted surfaces (types of paint products, prime and paint scheme surface, exterior emulsion paints, application processes); 

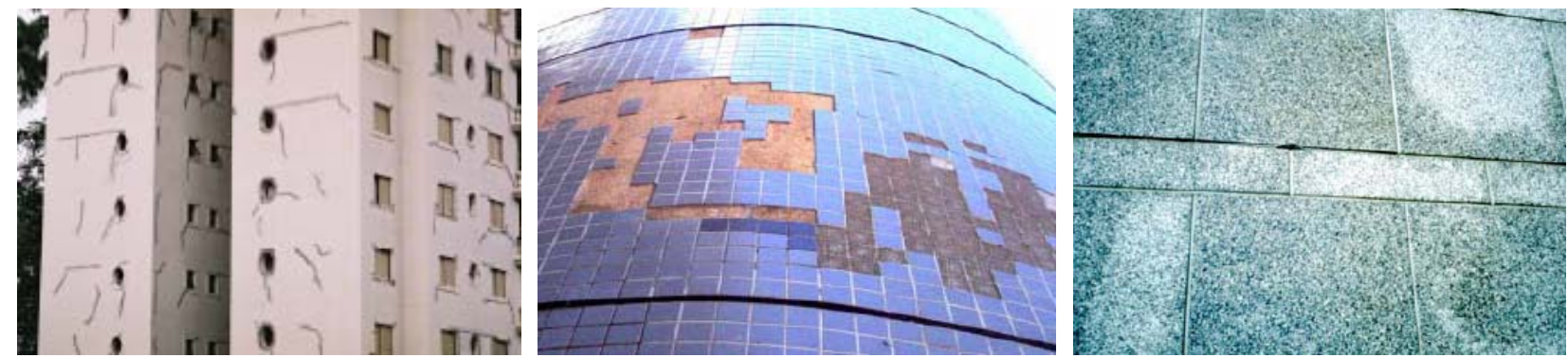

Fig. 2 Different type of materials applied as facade coatings.

- Anomalies: dust and dirt, lasting lotus leaf effect, covering power, insufficient resistance to air permeability or weatherproof isolation, damaged stones or ceramic tiles, alkali and smear effect, efflorescence, fractures and fissures;

- Repair works: surface cleaning, wire truss reinforcing, cleaning and pointing of stonework joints, removing and replacement of ceramic wall tiles, removing damaged paint and paint surface, preparing and refinishing stone panels.

\subsection{Characteristics of the Materials Used in Facades}

Depending on the role that the facade coatings play on the wall as a whole they can be classified as finishing, sealing or thermal insulation. The most frequent materials used as coating finishes are painting, tiling and, as sealing coating of the natural stone:

- Paint coating contributes to the aesthetic quality of the building and its environment and also protects the surface of the exterior wall against corrosion, deterioration and penetration of aggressive agents [14]. In order to obtain a good performance as an exterior coating, several aspects must be considered, such as covering power and resistance to water, sunlight, chemical products and to the development of micro organisms;

- The ceramic coating consists essentially of tiling panels, cement and adhesive and the joints between the slabs. The application of ceramic tiling to building facades has considerable advantages particularly as some degree of waterproofing is afforded by the glazed surface along with a great resistance to acids, alkalis and vapor. Other advantages are that it does not need painting and that it can be easily applied or substituted during repair work [15];

- The use of natural stone in the coating of facade surfaces is a good solution both technically and aesthetically. The stone coating is composed of slabs of stone attached to the wall by a support system. The principal characteristics of the stones are: reduced water absorption, sufficient mechanical resistance to bending and impact, abrasion and shearing parallel to the face of the slabs [16].

\subsection{The Database}

The most frequent anomalies that occur in the coated facades were analyzed in order to create a data base linked to the virtual model that could support planning of inspections and maintenance strategies in buildings [17]. The database contains the identification of anomalies that can be found in each type of material used in facades and the corresponding probable cause. For each kind of anomaly the most adequate repair solutions are also selected and included in the data base. The following example concerning deficiencies in tiles presents the methodology implemented in this virtual application (Table 1).

The characteristics related to anomalies, causes, repair solutions and rehabilitation tasks were included in a database of each type of material and linked to the $3 \mathrm{D}$ model of the building. Thus, the virtual model gives users the ability to transmit, visually and interactively, information related to the closure properties of exterior walls, allows them to analyze the anomalies observed in an inspection of the real building and to predict the corresponding repair work. The 3D virtual model can 
be seen, therefore, as an important tool for anomaly surveillance in structures and for supporting decision-making based on the visual analysis of alternative repair solutions.

\subsection{The Interface}

The implementation of the prototype system makes use of graphical software programming, Visual Basic 6.0 Microsoft, software to establish an adequate database, Microsoft office access, graphical drawing system, AutoCAD Autodesk and VR technology based software, EON Studio.

Human perceptual and cognitive capabilities were taken into account when designing this visualization tool so the model is easy to use and does not require sophisticated computer skills: many potential users are not computer experts. It uses an interactive 3D visualization system based on the selection of elements directly within the virtual 3D world. Furthermore, associated with each component, there are integrated databases, allowing the consultation of the required data at any point in time. The interface is composed of a display window allowing users to interact with the virtual model, and a set of buttons for inputting data and displaying results (Fig. 3).

For each new building to be monitored the characteristics of the environment (exposure to rain and sea) and the identification of each element of the facades must be defined. The data associated to each element are the building orientation, the type of exterior wall (double or single), and the area and type of coating. Once each monitored element has been

Table 1 Example of anomalies and the associated repair solution.

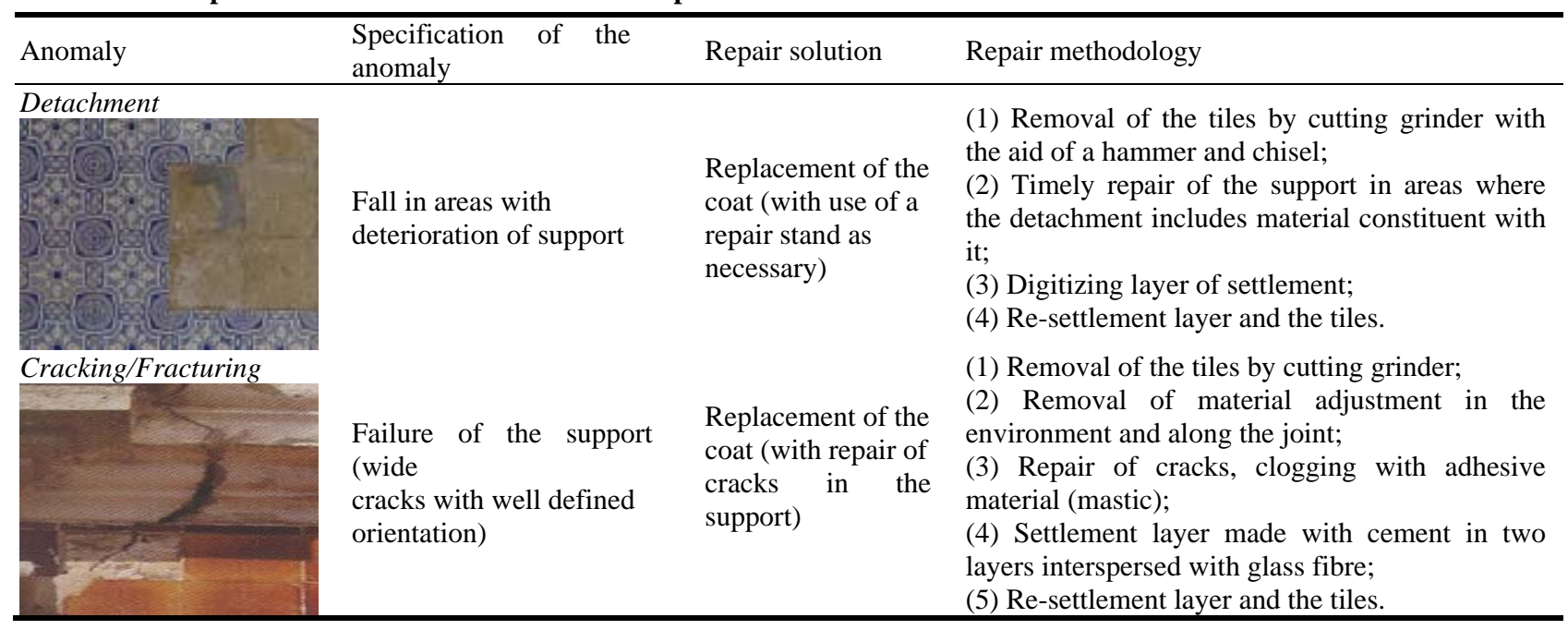

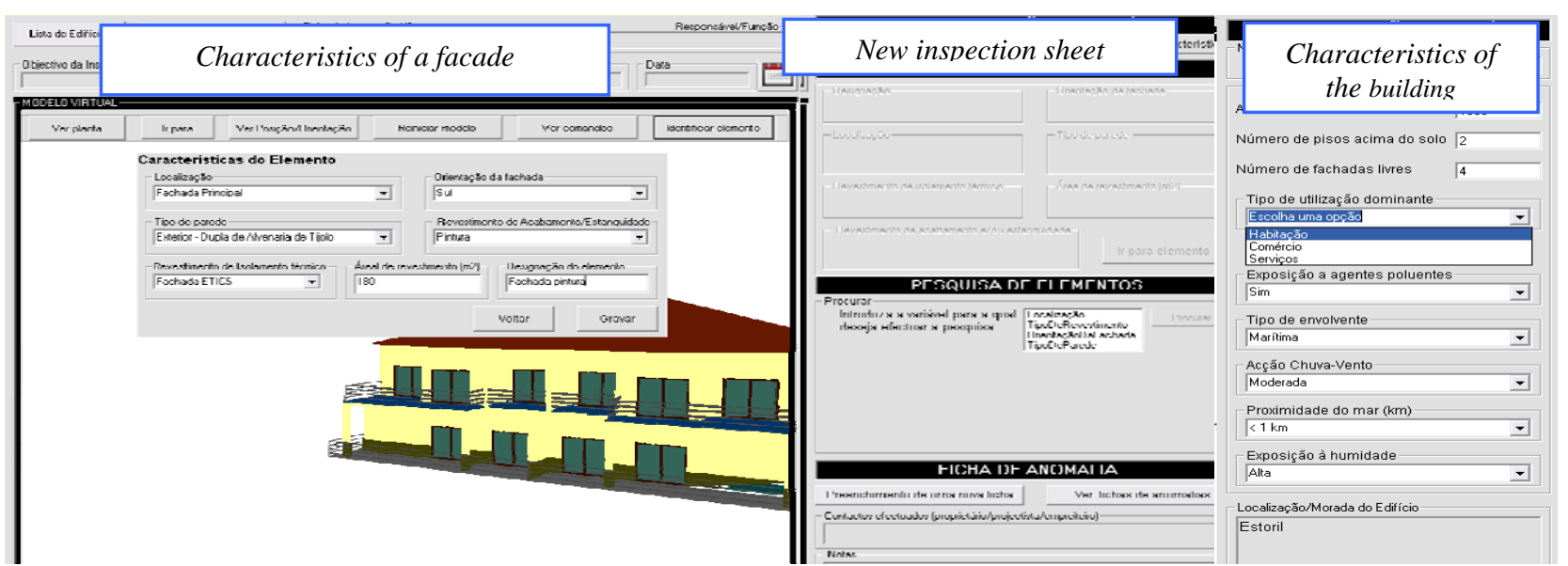

Fig. 3 The main interface of the interactive application. 
characterized, several inspection reports can be defined and recorded and thereafter consulted when needed. An inspection sheet is accessed by the main interface (Fig. 4).

Using the drop-down menus allowed by the interface, the user can associate the characteristics of the observed anomaly to: a facade element; the type of anomaly, the specification, details and the probable cause of the anomaly, an adequate repair solution and pictures taken in the building. After completing all fields relating to an anomaly, the user can present the report as a PDF (portable document file) file.

\subsection{The Case Study}

First, the 3D geometric model of a building case was created. The building consists of a ground-floor, a 1st floor and an attic with dwelling space shown. The coating elements of the walls were then modeled as independent geometric objects (Fig. 5). In this way, each element can then support characterization data of the applied material and different kinds of information related to maintenance.

All coatings studied were considered in this case-study. Thus it was assumed that the main facade is covered with tile and the remaining facades are painted while hall facades are of natural stone. Fig. 6 shows how to identify a facade in the virtual model of the building. The Fig. 7 includes the inspection report of the anomaly considered in Table 1.

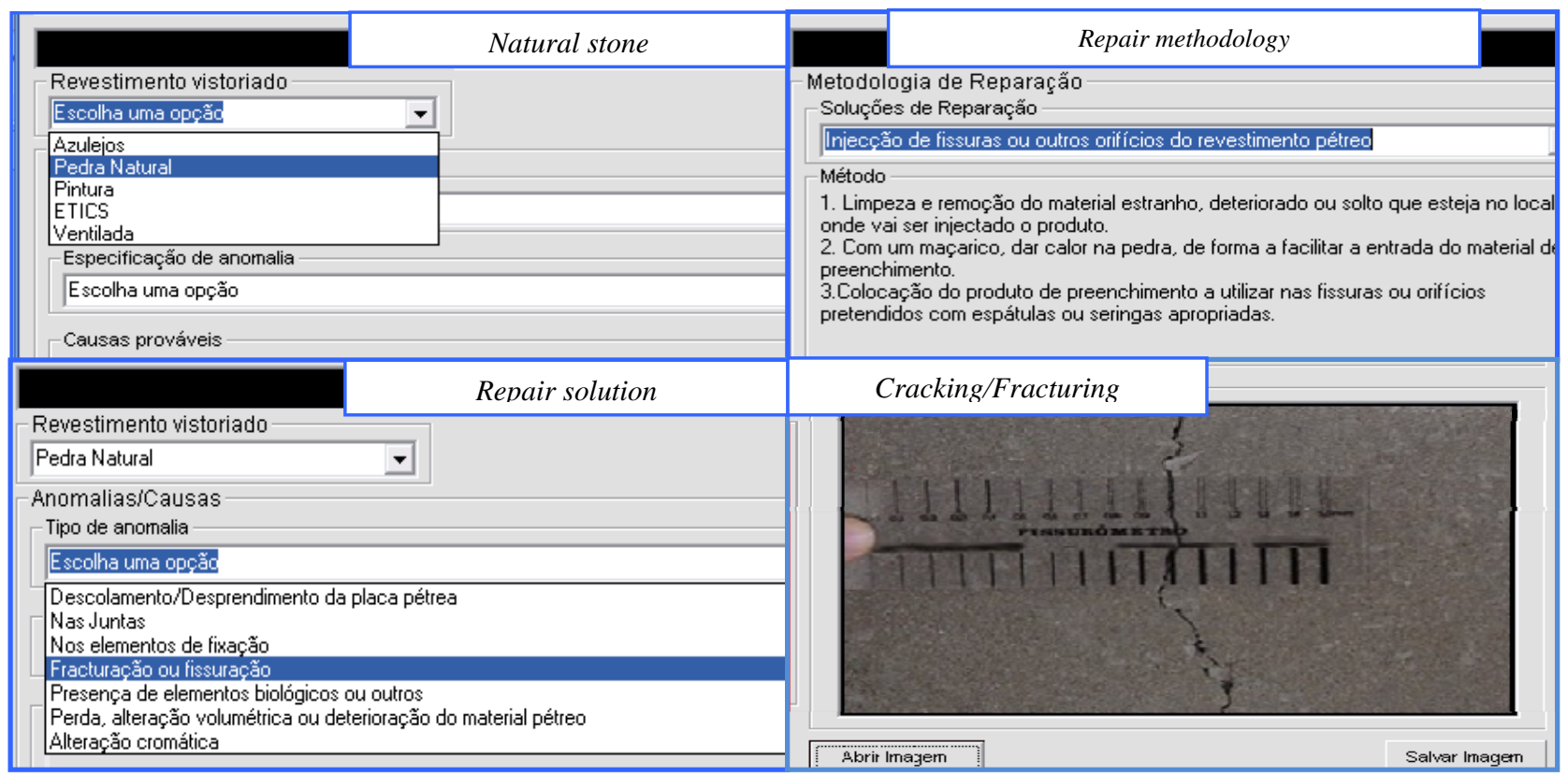

Fig. 4 Inspection sheet interface.
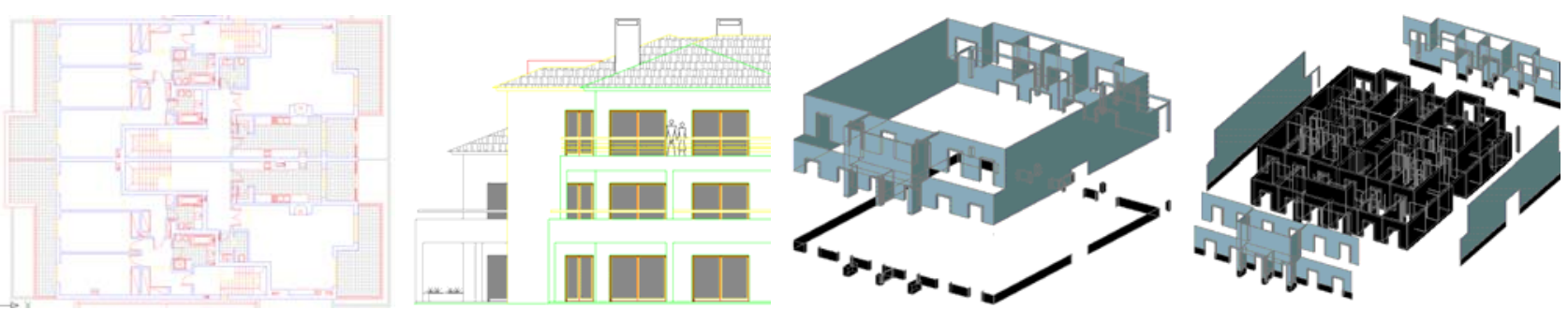

Fig. 5 Steps of the geometric modelling process. 


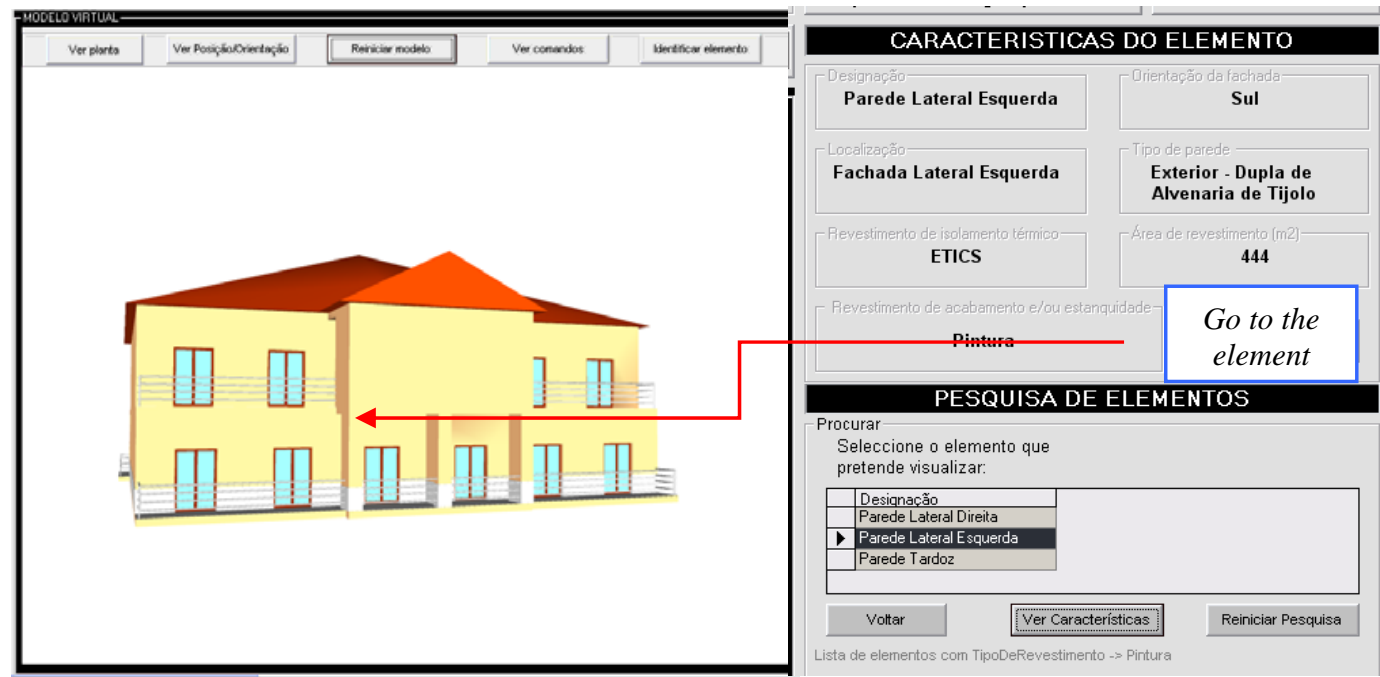

Fig. 6 Identification of a facade element.

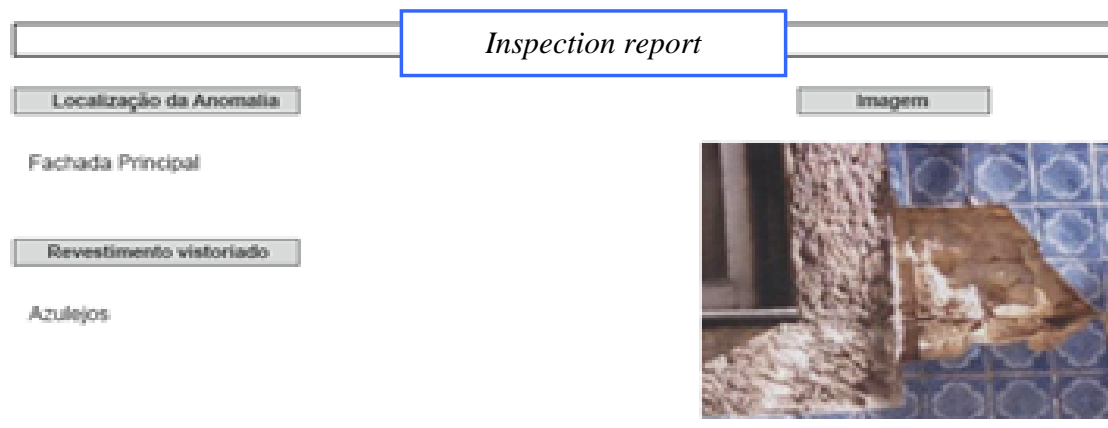

\begin{tabular}{|c|c|c|}
\hline \multicolumn{3}{|c|}{ 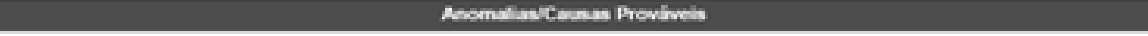 } \\
\hline Thpode anomala & \multicolumn{2}{|l|}{ Desprendimento } \\
\hline Especificaça de momala & \multicolumn{2}{|l|}{ Queda em zonas com degradą̧̃o do susorte } \\
\hline Causin proviveis & \multicolumn{2}{|c|}{$\begin{array}{l}\text { Movimentos no suporte por assentamentos diferenciais das fundaybles e alterąles } \\
\text { da geometra da parede. }\end{array}$} \\
\hline \multicolumn{3}{|c|}{ Carncteribey ib da ansmilla } \\
\hline \multicolumn{2}{|c|}{ Zona correnbe (xc), remates (bh, cantos salientes (ca) ceu cantos reentrantes $(c)$} & $R$ \\
\hline \multicolumn{2}{|c|}{ Drea de revestimento afectada $\left.\left(\mathrm{m}^{2}\right) \mathrm{m}\right)$} & 2 \\
\hline \multicolumn{3}{|c|}{ 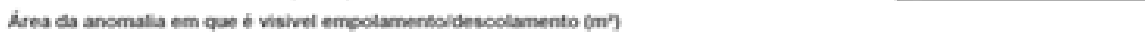 } \\
\hline \multicolumn{2}{|c|}{ Area da anomalis em que ocorre desprendimento im? } & {$[0,5$} \\
\hline \multicolumn{2}{|c|}{ Degradacilo do material de ansentamento (m), das fixap̧öes if ou do suporte (is) } & $s$ \\
\hline \multicolumn{2}{|c|}{ Nhura mixima a que cocere a anomala na fachada $(m)$} & 15 \\
\hline \multicolumn{2}{|c|}{ Protecoples arouinectidnicas em fachadas } & 5 \\
\hline \multicolumn{3}{|l|}{ Larpura mbala das fendas finm } \\
\hline \multicolumn{2}{|l|}{ Anomalia estabilicrada (SN) } & H \\
\hline \multicolumn{2}{|c|}{ Valor estitico das ronas alectadas : allo (A) médio (M) Dasxo (B) } & A \\
\hline \multicolumn{2}{|c|}{ Nivet ce gravidade: atto (N) midio (M) baiko (0) } & L \\
\hline \multicolumn{3}{|c|}{ Metodologia de reparacilo } \\
\hline Solopao de reparaças & \multicolumn{2}{|c|}{ Substhuiglo do revestimento (com recaras bo porbal do suporte) } \\
\hline mesodo & \multicolumn{2}{|c|}{ 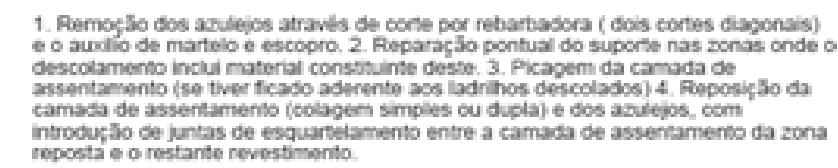 } \\
\hline Cuntos & 0.00 Euros & \\
\hline
\end{tabular}

Fig. 7 Inspection sheet report. 


\section{The Interior Walls}

An identical analysis of the characteristics, anomalies and repair works concerning the interior finish materials was carried out. With this information a data base was created (Fig. 8).

Another inspection interface was defined for the painted surfaces of interior walls, also associated to repair solutions and corresponding methodologies of rehabilitation (Fig. 9).

In addition the model identifies the period of time between the application of new paint and the predicted time when the next paint will be needed. The color changes between white (new) and red (when an area needs to be painted again (Fig. 10). The data of periodic on-site inspections included in preventive maintenance is taken into account for each monitored element of the interior wall. Thus, when the date of interaction with the prototype is compared with the date predicted for the new paint application, the correspondent RGB (red, green and blue) values are calculated.

Different RGB values generate different color, using this virtual model. Therefore, by using data visualization supported by this VR technology, it is possible to estimate whether the wall needs painting immediately or not.
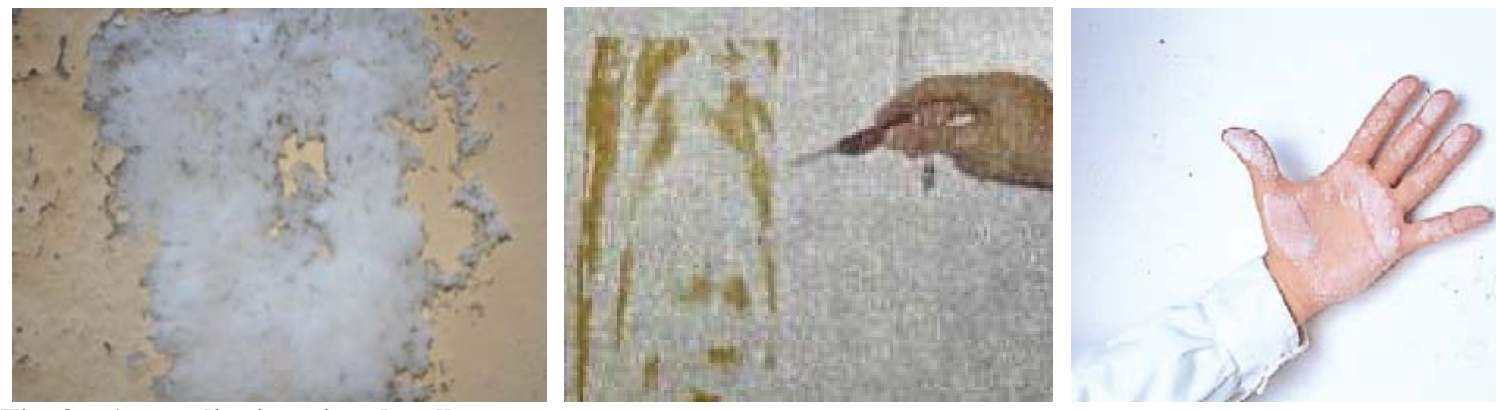

Fig. 8 Anomalies in painted walls.

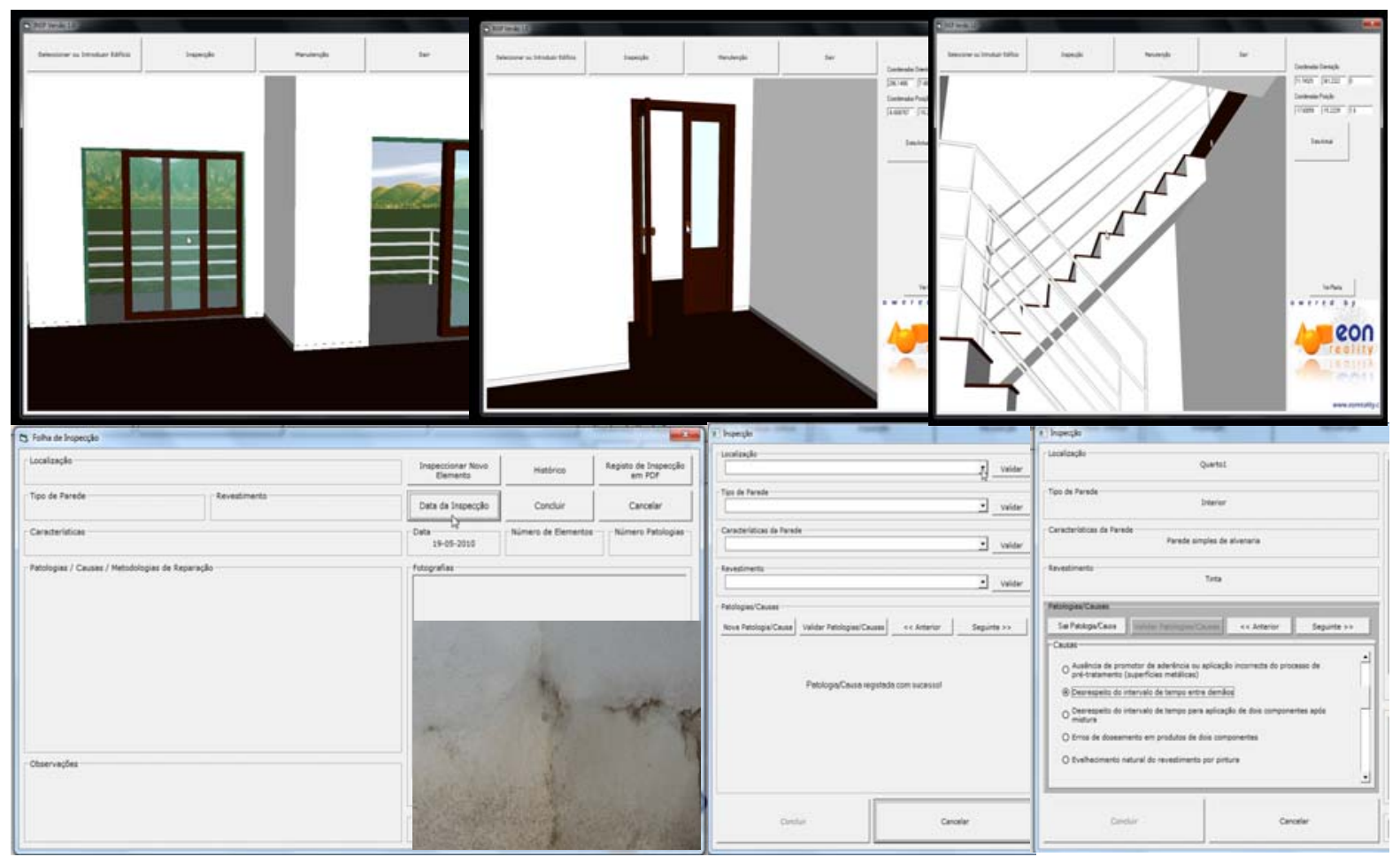

Fig. 9 Painted coating of interior walls and the inspection interface. 


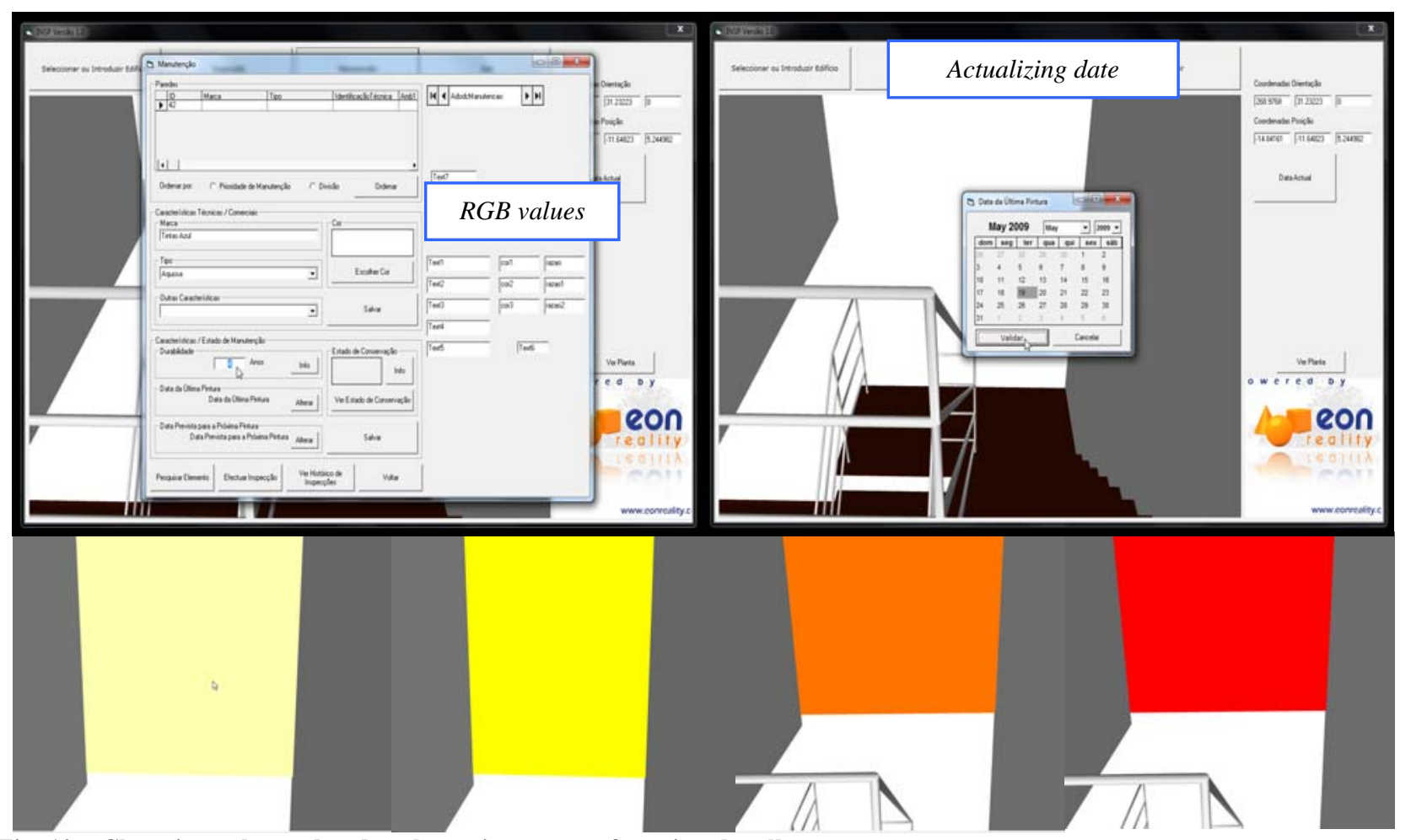

Fig. 10 Changing colors related to the maintenance of a painted wall.

\section{Conclusions}

A VR model to support the maintenance of walls in a building was developed within a research project. It enables the visual and interactive transmission of information related to the physical behavior of the elements, defined as a function of the times variable. The model shows the characteristics of each element of the building in the model and the information related to inspection, anomalies and repair works. As the 3D model is linked to a data base in an interactive environment and has a friendly interface to deal with this knowledge, it allows a collaborative system. The work is still in progress. With this application the user may fully interact with the program referring to the virtual model at any stage of the maintenance process and analyze the best solution for repair work. It can also support the planning of maintenance strategies. The developed software is easy to handle and transport for on-site inspections and comprises information of the causes, solutions and methods for repairing.

\section{Acknowledgments}

The authors gratefully acknowledge the financial support of the Foundation for Science and Technology, a Governmental Organization for the research project PTDC/ECM/67748/2006, Virtual Reality technology applied as a support tool to the planning of construction maintenance, now in progress.

\section{References}

[1] A. Z. Sampaio, M. M. Ferreira and D. P. Rosário, Interactive virtual application on building maintenance: The lighting component, in: 3rd International Conference on Integrity, Reliability and Failure: Challenges and Opportunities, Symposium Visualization and human-Computer Interaction, Porto, Portugal, July 20-24, 2009, pp. 221-222.

[2] EON system, Introduction to working in EON Studio 5.5, EON Reality Inc., available online at: http://www.eonreality.com/.

[3] M. Fisher, J. Haymaker and K. Liston, Benefits of 3D and 4D models for facility managers and AEC service providers, in: 4D CAD and Visualization in Construction: Developments and Applications, A. A. Balkema Publishers, Lisse, 2003, pp. 1-32. 
[4] Stanford University, Dept. of Civil and Environmental Engineering, Group 4D CAD Research, available online at: http://www.stanford.edu/group/4D/projects/projects.htm.

[5] VTT Technical Research Centre of Finland, Building \& Built Environment, available online at: http://www.vtt.fi/services/cluster6/index.jsp.

[6] J. Leinonen and K. A. A. Kähkönen, New construction management practice based on the Virtual Reality technology, in: R. A. Issa Raja, F. Ian, W. J. O’Brien (Eds.), 4D CAD and Visualization in Construction: Developments and Applications, American Society of Civil Engineers, USA, 2003, pp. 75-100.

[7] F. Petzold, O. Bimber and O. Tonn, CAVE without CAVE: On-site visualization and Design Support in and within existing building, in: 25th Conf. of Education and Research in Computer Aided Architectural Design in Europe, Frankfurt, Germany, 2007, pp. 161-168.

[8] A. Khanzode, M. Fisher and D. Reed, Challenges and benefits of implementing virtual design and construction technologies for coordination of mechanical, electrical, and plumbing systems on large healthcare project, in: Proc. CIB 24th W78 Conference, Maribor, Slovenia, 2007, pp. 205-212.

[9] A. L. Lindholm, A constructive study on creating core business relevant CREM strategy and performance measures, Facilities Journal 26 (7-8) (2008) 343-358.

[10] H. N. Rad, Visualization of building maintenance through time, in: Proc. of the IV'97, IEEE 1st International
Conference on Information Visualization, 1997, pp. 308-314.

[11] F. Khosrowshahi and E. Banissi, Visualisation of the degradation of building flooring systems, in: IEEE Conference, Information Visualisation \& Computer Society, London, 2001, pp. 507-513.

[12] A. Z. Sampaio and P. G. Henriques, Building activities visualized in virtual environments, in: 25th Conf. of Education and Research in Computer Aided Architectural Design in Europe, Frankfurt, Germany, 2007, pp. 85-89.

[13] A. M. Gomes and A. P. Pinto, Didactic Text of Construction Materials, Technical University of Lisbon, Lisbon, Portugal, 2009.

[14] C. Lopes, Color anomalies in coatings for painted exterior walls, Master Thesis, TU Lisbon, Portugal, 2008. (in Portuguese)

[15] L. Ferreira, J. Coroado, V. Freitas and I. Maguregui, Causes the fall of tiles applied in exteriors of buildings: Standard tiling in 1850-1920 buildings, in: 3rd Meeting on Pathology and Rehabilitation of Buildings, Oporto, Portugal, Mar. 18-20, 2009, pp. 88-110. (in Portuguese)

[16] M. Veiga and S. Malanho, Natural stone coatings: Methodology of diagnosis and repair of anomalies, in: 3rd Meeting on Pathology and Rehabilitation of Buildings, Oporto, Portugal, Mar. 18-20, 2009, pp. 3-13. (in Portuguese)

[17] A. R. Gomes, Virtual reality technology applied to the maintenance of facades, Master Thesis, TU Lisbon, Portugal, 2010. 